\title{
Bolus Infusion Procedure
}

National Cancer Institute

\section{Source}

National Cancer Institute. Bolus Infusion Procedure. NCI Thesaurus. Code C15678.

A procedure in which a single dose of a pharmalogical substance is administered, generally via injection, over a short period of time. 